\title{
Inequalities in the Use of Family Planning in Rural Nepal
}

\author{
Suresh Mehata, ${ }^{1}$ Yuba Raj Paudel, ${ }^{2}$ Bhogendra Raj Dotel, ${ }^{3}$ Dipendra Raman Singh, ${ }^{3}$ \\ Pradeep Poudel, ${ }^{1}$ and Sarah Barnett ${ }^{4}$ \\ ${ }^{1}$ Nepal Health Sector Support Programme, Ministry of Health and Population, Ramshah Path, Kathmandu 44600, Nepal \\ ${ }^{2}$ Karuna Foundation Nepal, Baluwatar, Kathmandu 44616, Nepal \\ ${ }^{3}$ Ministry of Health and Population, Ramshah Path, Kathmandu 44600, Nepal \\ ${ }^{4}$ Options Consultancy Services Limited, Devon House, 58 St Katharine's Way, London E1W 1LB, UK
}

Correspondence should be addressed to Sarah Barnett; sarahalbarnett@gmail.com

Received 9 June 2014; Revised 4 August 2014; Accepted 7 August 2014; Published 28 August 2014

Academic Editor: Luenda Charles

Copyright (C) 2014 Suresh Mehata et al. This is an open access article distributed under the Creative Commons Attribution License, which permits unrestricted use, distribution, and reproduction in any medium, provided the original work is properly cited.

\begin{abstract}
This paper explores inequalities in the use of modern family planning methods among married women of reproductive age (MWRA) in rural Nepal. Data from the 2012 Nepal Household Survey (HHS) were utilized, which employed a stratified, threestage cluster design to obtain a representative sample of 9,016 households from rural Nepal. Within the sampled households, one woman of reproductive age was randomly selected to answer the survey questions related to reproductive health. Only four out of every ten rural MWRA were using a modern family planning method. Short-acting and permanent methods were most commonly used, and long-acting reversible contraceptives were the least likely to be used. Muslims were less likely to use family planning compared to other caste/ethnic groups. Usage was also lower among younger women (likely to be trying to delay or space births) than older women (likely to be trying to limit their family size). Less educated women were more likely to use permanent methods and less likely to use short-term methods. To increase the CPR, which has currently stalled, and continue to reduce the TFR, Nepal needs more focused efforts to increase family planning uptake in rural areas. The significant inequalities suggest that at-risk groups need additional targeting by demand and supply side interventions.
\end{abstract}

\section{Introduction}

In Nepal, the National Health Policy (1991), the Second LongTerm Health Plan (1997-2017), and the National Reproductive Health Strategy (1998) have all emphasized the need to improve equitable access to quality reproductive health services. Since 2010, it has been government policy to provide at least five different family planning methods at all levels of health facility from health post and above [1]; however, just $8 \%$ of health posts have met this target [2]. In the community, injectable contraceptives are available from Community Health Workers (CHWs), and Female Community Health Volunteers (FCHVs) undertake educational and promotional activities on family planning and distribute oral contraceptive pills and condoms [1].

Many barriers prevent the use of family planning and result in unplanned pregnancies [3]. These barriers are multifactorial, including both client-related factors such as a lack of education and exposure to media resulting in poor knowledge about family planning methods and services [3], low economic status [3], and concerns and experience of side effects [3] and health system factors such as poor coverage of health facilities [4], lack of outreach services [4], stockouts and poor method mix [3], limited providers and poor provider competence [4], and lack of advice and counselling [4]. Both client- and system-related barriers contribute to increased inequality in the utilization of family planning services.

Between 1996 and 2006 the national contraceptive prevalence rate (CPR) increased by $69 \%$ in Nepal, from $26 \%$ in 1996 [5] to $44 \%$ in 2006 [6], but between 2006 and 2011 it stalled [7] (Figure 1). Similarly, the CPR in rural areas increased from $24 \%$ in 1996 [5] to $42 \%$ in 2006 [6] but then stalled between 2006 and 2011. A different pattern was observed in urban areas: the CPR increased from $45 \%$ in 1996 to $56 \%$ in 2001 [8] but then declined to $50 \%$ in 2011 [7]. Despite the stalled 


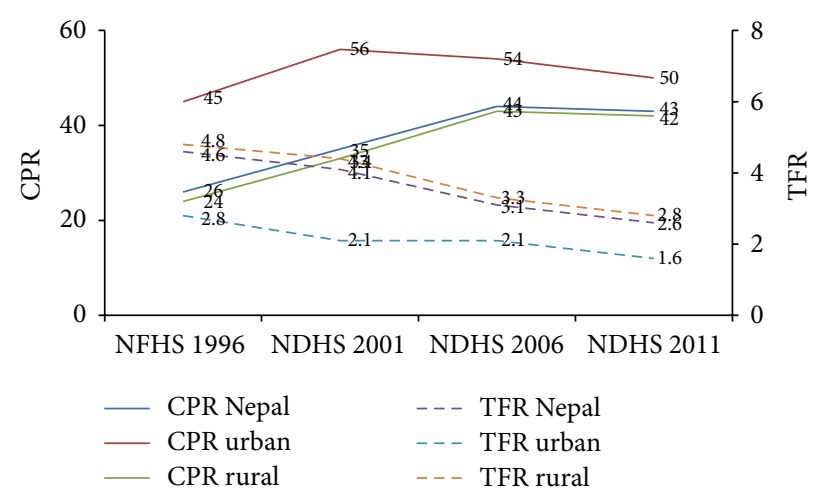

FIGURE 1: CPR and TFR in Nepal, 1996-2011, disaggregated by urban and rural residence. Sources: Nepal Family Health Survey 1996; Nepal Demographic Health Survey 2001; Nepal Demographic Health Survey 2006; and Nepal Demographic Health Survey 2011.

CPR in rural areas and the decreased CPR in urban areas, the TFR has continued to decline in both: from 2.8 in 1996 [6] to 1.6 in 2011 [7] in urban areas and from 4.8 in 1996 [6] to 2.8 in 2011 [7] in rural areas. However, the decline in the TFR may be due to the momentum gained in last decade, and if substantial efforts are not put in place now to increase the CPR it is unlikely that this decline will continue.

Given that most of the Nepalese population live in rural areas $(83 \%)$, the national CPR and total fertility rate (TFR) are aligned to the rural figures and a better understanding of inequalities in family planning use within rural areas is required to inform efforts to meet the national MDG target for the TFR of 2.5. Many studies have documented lower availability and use of family planning methods in rural areas $[9,10]$ and inequalities between different groups [11]. Rural women often have lower levels of education and lower socioeconomic status, which may reduce access to family planning [12], and input into decision making [13].

The objective of this paper is to assess the prevalence and inequalities (by age, level of education, economic status, caste/ethnicity, access to health facility, and ecological zone) in the use of modern family planning methods, among married women of reproductive age in rural Nepal.

\section{Methodology}

2.1. Study Design and Sampling. This paper used data collected between August and September 2012 for the nationally representative, cross-sectional 2012 Nepal Household Survey (HHS 2012) coordinated by authors of this paper, in collaboration with the Ministry of Health and Population (MoHP). The primary objective of the survey was to provide national estimates for key reproductive, maternal, neonatal, and child health indicators [14]. Since some of the survey questions related to the uptake of family planning, the MoHP was keen to see further analysis of these data to explore inequalities in family planning in rural Nepal.

Nepal consists of 75 districts divided into three ecological zones (mountain, hill, and Terai), five administrative regions, and 13 subregions. Districts are divided into village development committees (VDCs) (considered to be rural) and municipalities (considered to be urban). These in turn are divided into wards, with each VDC having nine wards. A stratified, three-stage cluster design was employed in the HHS 2012, first selecting districts, then wards, and then households. Districts were the primary sampling units (PSUs), and one PSU was randomly selected from each of the 13 subregions. This resulted in three districts being selected from the mountain zone, five from the hill zone, and five from the Terai zone. Within these 13 PSUs, wards were used as the basis for clusters, and 180 clusters were selected with probability proportionate to size (PPS) (based on the number of households as per the National Population and Housing Census 2011) [15]. From each cluster, 57 households were selected using systematic sampling to obtain a representative sample of 10,260 households of which 9,016 were in rural areas. Within the sampled households, one woman of reproductive age (15-49 years) was randomly selected to answer the survey questions related to reproductive health. However, the current analysis is based on responses from 7442 married women of reproductive age (15-49 years) from the rural households. A more detailed description of the sampling methodology is presented in the HHS 2012 report [14].

2.2. Data Entry and Coding. All questionnaires were checked by a supervisory level at the time of data collection and coding of data was undertaken prior to data entry. All data were double entered into a CSPro 4.0 database and any inconsistencies were corrected. Data entry was closely supervised by a data manager. Prior to analysis data were checked for any anomalies and, where necessary, data were cross-checked with the original questionnaires.

2.3. Variables Included. The main outcome variable was the use of any modern contraceptive. This was broken down into permanent, long-acting, and short-acting methods, and these categories were used in the multinomial logistic regression analysis as outcome variables. The use of these broader categories, as opposed to showing results by individual method, is more relevant for government efforts to improve service delivery. Three levels of predictor variables were available from the HHS 2012 and were included in the analysis: individual (mother's age: 15-24 years, 25-34 years, and 3549 years; maternal education: never attended school to higher education); household (caste/ethnic group categorized based on the classification recommended by Bennett et al. [16]; wealth quintile and distance to health facilities: less than 30 minutes, 30-60 minutes, and more than 60 minutes), and community (ecological zone: mountain, hill, and Terai).

2.4. Data Analysis. All analyses in this paper were conducted using STATA 12 SE Version. Prevalence values were weighted by sample weights to provide population estimates. The prevalence and 95\% confidence intervals (95\% CI) were calculated taking into consideration the complex survey design of the HHS 2012. The crude and adjusted odds ratios were assessed through binomial and multinomial logistic 
regression to estimate the inequalities, and a $P<0.05$ was considered as statistically significant. All of the predictors (mother's age, education, economic status, caste/ethnicity, distance to health facilities, and ecological zone) were used in the final adjusted model.

\section{Results}

3.1. Any Modern Methods. Forty-one percent of MWRA in rural Nepal were using a modern family planning method (Table 1). The uptake of modern family planning methods increased with age (Table 2). Compared to Brahmins/Chhetris, Newars were nearly twice as likely (AOR: 1.9; 95\% CI: 1.4-2.7) to use a modern method while Muslims and Terai Madhesi other castes were least likely. Women residing in hill districts were less likely to use a modern method than those in the mountain districts (AOR: 0.7; 95\% CI: 0.5-0.9). No significant differences in the use of modern methods were noted between wealth quintiles, levels of education, and the time taken to reach the nearest government health facility. The use of short-term (21\%) and permanent methods $(18 \%)$ was far higher than the use of long-acting reversible contraceptives (LARCs) (2\%) (Table 1).

3.2. Permanent Methods. Permanent methods (18\%) were the second most commonly used group of modern methods. The likelihood of using permanent methods increased with age (as attainment of desired family size increases with age) and was more common among those who had never been to school. The multinomial regression supported this finding showing that the likelihood of using a permanent method decreased with increasing education level (Table 2). Permanent methods were most likely to be used in the Terai (23\%) and the least likely to be used in the hill districts (12\%). There were large differences in the use of permanent methods by caste/ethnic group, with Terai Madhesi other castes having the highest use (27\%) and Muslims the lowest use (4\%) (Table 1). The multinomial logistic regression analysis showed low use of permanent methods among Janajatis (AOR: 0.7; 95\% CI: 0.5-0.9) and Muslims (AOR: 0.1; 95\% CI: 0.1-0.2) compared to Brahmins/Chhetris. No significant differences were observed in wealth quintile, time taken to the nearest government health facility, or ecological zone (Table 2).

3.3. Long-Acting Reversible Methods. Use of LARCs (implants and IUCDs) was very low, with around 2\% of MWRA using each method. Use of LARCs increased slightly for each agegroup up to the peak use at 35-49 years (Table 1). The multinomial logistic regression analysis also showed use of LARCs to be higher among those aged 35 years or above compared to those aged below 25 (AOR: 2.0; 95\% CI: 1.2-3.5). Use of LARCs among Terai/Madhesi other castes (AOR: 0.2; 95\% CI: 0.1-0.7) was lower than among Brahmins/Chhetris (Table 2). Use of LARCs was slightly higher among those who lived less than 60 minutes travel time from a government health facility in comparison to those living more than 60 minutes away (Table 1). Multinomial logistic regression analysis also showed that use of LARCs was lower among those who resided more than 60 minutes away from their nearest government health facility (AOR: 0.5 ; 95\% CI: 0.3-0.9) in comparison to those living less than 30 minutes away. No significant association was noted by ecological zone, wealth quintile, or level of education (Table 2).

3.4. Short-Term Methods. Short-term methods (21\%) were the most commonly used group of methods of contraception. MWRA aged 25-34 years were most likely to use short-term methods (24\%) among all age-groups, and those living in mountain $(25 \%)$ or hill (25\%) districts were more likely to use them compared to those living in Terai districts (15\%). Use of short-acting methods was the lowest for those who had never attended school (17\%) and the highest amongst the most educated (30\%). This was supported by the multinomial logistic regression analysis, which showed that women with higher education were nearly twice as likely (AOR: 1.8; 95\% CI: 1.1-2.6) to use a short-acting method compared to those who never attended school. The likelihood of using a shortacting method was higher among Newars and Janajatis than Brahmins/Chhetris, while Muslims were less likely to use short-acting method (Table 2). Those in the highest wealth quintile (23\%) were more likely to use short-acting methods compared to other wealth quintiles (Table 1). No significant association was observed with time taken to reach the nearest government health facility (Table 2).

\section{Discussion}

In rural Nepal the challenging topography and lack of road infrastructure and transportation mean that many have to walk long distances over difficult terrain to reach health facilities. The 2012 HHS found that just over half of the rural population (53\%) were within half an hour travel time of their closest health facility, compared to $80 \%$ in urban areas [14]. Distance to the nearest health facility has been identified as a barrier to family planning uptake in other studies $[12,17]$. A study in Bangladesh revealed that couples who resided more than 30 minutes travel time from a facility were $25 \%$ less likely, and those living between 15 and 30 minutes were $20 \%$ less likely, to use FP methods in comparison to women who lived at a distance of less than 15 minutes [18]. However, except for LARCs, no significant association was found in this study between distance to a health facility and use of modern family planning methods. This may be partly attributed to the increased availability of family planning methods (injectables, pills, and condoms) at community level through outreach clinics, private pharmacies, and FCHVs, whereas use of LARCs, which are only available at facilities, decreased with increasing distance. Male sterilization was higher among those living further from a government health facility (data not shown). Males often use mobile camps for sterilization $[7,19,20]$ and may be more likely to opt for sterilization if they face greater difficulties in accessing services for other family planning methods.

Use of female sterilization was most common among those living in the Terai, while male sterilization was least common in the Terai (data not shown). Male sterilization 


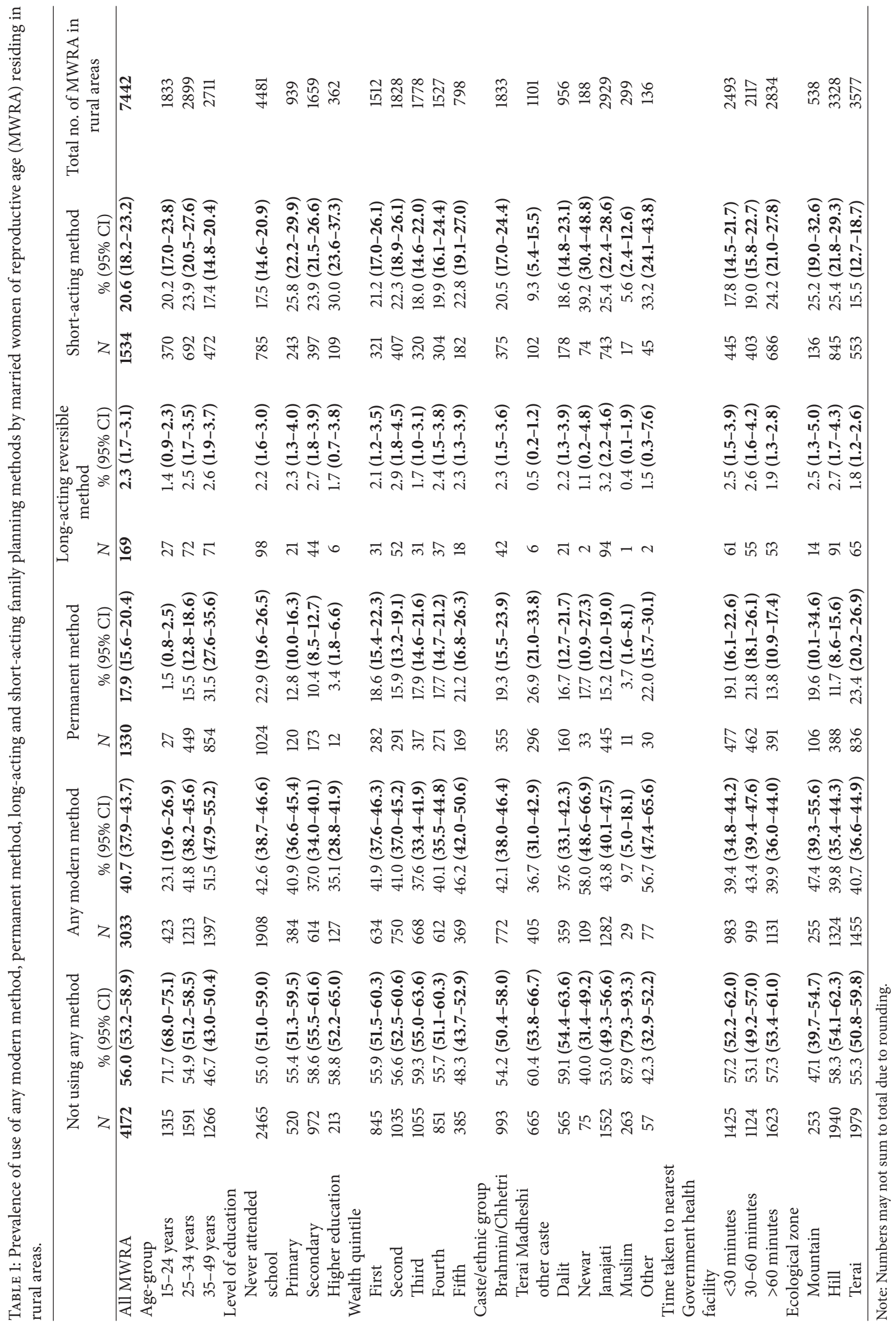




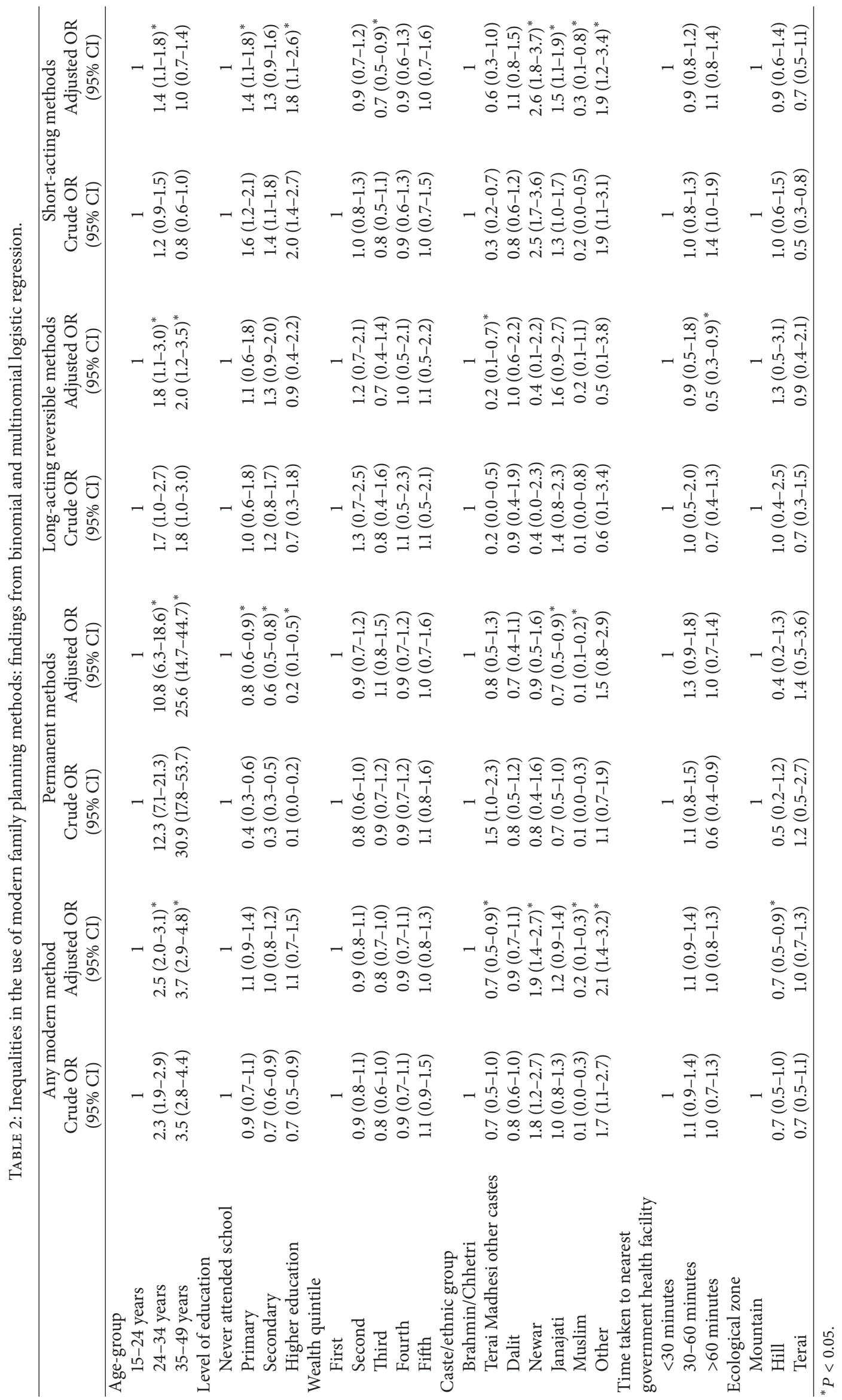


is sometimes believed to lead to impurity and exclusion from rituals and also cause physical weakness [21], but it is not clear whether this belief is more common in the Terai. Newars were most likely to use family planning methods and Muslims and Terai Madhesi other castes were least likely to use family planning methods. Similar findings have been reported in other studies [22]. Caste-based discrimination has been reported by Dalits, Muslims, and Terai Madhesi other castes at health facilities in regard to reduced access to care, delayed care, and poor quality of care, including reluctance by service providers to touch Dalits leading to fewer physical examinations and discourteous behaviour [23]. Continuing social exclusion also results in families not visiting health facilities to avoid potential discrimination and poor quality care [23-25].

Studies have reported increased use of family planning with increased education [25-27]. This paper showed that the use of permanent methods (male and female) was greater among those who have never attended school. This may reflect the higher use of sterilization among older couples, as they have already attained their desired family size, who were less likely to have attended school [7]. The use of shortterm methods was almost double among those who had higher education compared to those who had never attended school. Use of contraceptives increased with age, contrary to the NDHS, which found that use was lower among younger and older women [7]. Other studies have reported higher contraceptive use among those with higher economic status [25-27], but this paper did not show a significant association.

The findings from current analysis present some implications for policy and future research. First, since use of LARCs has been found to be significantly associated with distance between health facility and home, women residing far away need to be reached through satellite, mobile, or outreach clinics [28] or by supplying LARCs through lower-level health facilities. Furthermore, short-term family planning methods can also be promoted through these clinics [20]. This could increase the CPR in rural areas because LARCs, especially implants, are becoming popular among MWRA in rural Nepal [29]. Second, efforts should also be made to increase FP use by Muslims, Dalits, and Terai Madhesi other castes. One approach to increase FP adoption could be to train the same caste health workers [30] to provide FP services in such areas or to orientate existing health workers in accountability and interpersonal communication. Third, given the link between education and use of family planning, female education and women's empowerment should be high on the agenda. Fourth, interaction with health providers during antenatal, delivery, postnatal care, and child health visits is an ideal opportunity to promote FP use, especially given that younger women had significantly higher unmet need for spacing during 2 years postpartum [31].

\section{Conclusions}

To increase the national CPR, which has currently stalled, and to ensure that the TFR continues to decline, additional efforts need to be focused on rural Nepal, including addressing the significant inequalities that exist. The findings from this paper suggest that efforts to supply LARCs within 30 minutes walking distance from homes in rural areas are likely to increase uptake. High risk groups, with lower use of family planning, such as Muslim, younger, and less educated women, need additional targeting by demand and supply side interventions.

\section{Ethical Approval}

Ethical approval for the 2012 HHS was received from the Ethical Review Board of the Nepal Health Research Council. Permission was also obtained from the relevant authorities in the selected districts and VDCs. Verbal consent was taken from all of the participants, after explaining the purpose of the research and guaranteeing the confidentiality of any information given.

\section{Conflict of Interests}

The authors have no conflict of interests to declare.

\section{Authors' Contribution}

Suresh Mehata, Sarah Barnett, and Bhogendra Raj Dotel developed the concept for this paper. Suresh Mehata and Yuba Raj Paudel carried out the literature search and data analysis. Dipendra Raman Singh, Pradeep Poudel, and Sarah Barnett advised on the methodology and interpretation of findings. Suresh Mehata wrote the first draft. Bhogendra Raj Dotel, Sarah Barnett, Pradeep Poudel, Dipendra Raman Singh, and Yuba Raj Paudel critically reviewed and revised the draft paper. All authors read and approved the final paper.

\section{Acknowledgment}

The Household Survey 2012 was funded by the UK Department for International Development (DFID).

\section{References}

[1] MOHP, Nepal Health Sector Programme-Implementation Plan 2010-2015, Ministry of Health and Population, Kathmandu, Nepal, 2010.

[2] S. Mehata, S. C. Lekhak, P. B. Chand, D. R. Singh, P. Poudel, and S. Barnett, Service Tracking Survey, Ministry of Health and Population (MOHP), Government of Nepal, Kathmandu, Nepal, 2013.

[3] M. Campbell, N. N. Sahin-Hodoglugil, and M. Potts, "Barriers to fertility regulation: a review of the literature," Studies in Family Planning, vol. 37, no. 2, pp. 87-98, 2006.

[4] S. Hamid and R. Stephenson, "Provider and health facility influences on contraceptive adoption in urban Pakistan," International Family Planning Perspectives, vol. 32, no. 2, pp. 71-78, 2006.

[5] A. Pradhan, R. H. Aryal, G. Regmi, B. Ban, and P. Govindasamy, Nepal Family Health Survey 1996, Ministry of Health and Population, New ERA, Kathmandu, Nepal; Macro International, Calverton, Md, USA, 1997. 
[6] MOHP, Nepal Demographic and Health Survey 2006, Ministry of Health and Population, New ERA, and ICF International, Calverton, Md, USA, 2007.

[7] MOHP, "Nepal Demographic and Health Survey 2011," Ministry of Health and Population, New ERA, and ICF International, Calverton, Md, USA, 2012.

[8] MOH, New ERA, and ORC Macro, Nepal Demographic and Health Survey 2001, Family Health Division, Ministry of Health, New ERA and ORC Macro, Calverton, Md, USA, 2002.

[9] R. E. Lightbourne, "Urban-rural differentials in contraceptive use," United States Agency for International Development (USAID), http://www.popline.org/node/450779.

[10] N. Chandhick, B. S. Dhillon, I. Kambo, and N. C. Saxena, "Contraceptive knowledge, practices and utilization of services in the rural areas of India (an ICMR task force study)," Indian Journal of Medical Sciences, vol. 57, no. 7, pp. 303-310, 2003.

[11] NFHP II, Family Planning, Maternal, Newborn and Child Health Situation in Rural Nepal: A Mid-term Survey for NFHP II, Nepal Family Health Program II and New ERA, Kathmandu, Nepal, 2010.

[12] R. B. Rayamajhi, A. Ghimire, S. Niraula, S. Budhathoki, V. Khanal, and P. Pokharel, "A descriptive study on contraceptive practices among mothers," Journal of Chitwan Medical College, vol. 3, no. 4, pp. 34-37, 2014.

[13] D. Bhattarai and O. B. Panta, "Knowledge attitude and practice on contraception in village women in Khotang," Journal of Nepal Health Research Council, vol. 11, no. 23, pp. 40-43, 2013.

[14] S. Mehata, S. C. Baral, P. B. Chand, D. R. Singh, P. Poudel, and S. Barnett, Nepal Household Survey, Ministry of Health and Population (MOHP), Government of Nepal, Kathmandu, Nepal, 2013.

[15] CBS, National Population and Housing Census 2011, vol. 1, CBS, Kathmandu, Nepal, 2012.

[16] L. Bennett, D. R. Dahal, and P. Govindasamy, "Caste, Ethnic, and Regional Identity in Nepal: Further Analysis of the 2006 Nepal Demographic and Health Survey," Nepal Ministry of Health and Population, New ERA, and ICF International, Calverton, Md, USA, 2008.

[17] J. T. Bertrand, E. Seiber, and G. Escudero, "Contraceptive Dynamics in Guatemala: 1978-1998," International Family Planning Perspectives, vol. 27, no. 3, pp. 112-118, 2001.

[18] A. Levin, B. K. Caldwell, and Barkat-e-Khuda, Demand for Family Planning Services in Rural Bangladesh: Effect of Cash Prices and Access, International Centre for Diarrhoeal Disease Research, Dhaka, Bangladesh, 1997.

[19] H. Nazerali, S. Thapa, M. Hays, L. R. Pathak, K. R. Pandey, and D. C. Sokal, "Vasectomy effectiveness in Nepal: a retrospective study," Contraception, vol. 67, no. 5, pp. 397-401, 2003.

[20] S. S. Padmadas, F. Amoako Johnson, T. Leone, and G. P. Dahal, "Do mobile family planning clinics facilitate vasectomy use in Nepal?” Contraception, vol. 89, no. 6, pp. 557-563, 2014.

[21] G. P. Dahal, S. S. Padmadas, and P. R. A. Hinde, "Fertilitylimiting behavior and contraceptive choice among men in Nepal," International Family Planning Perspectives, vol. 34, no. 1, pp. 6-14, 2008.

[22] M. N. Khanal, D. R. Shrestha, P. D. Panta, and S. Mehata, "Impact of Male Migration on Contraceptive Use, Unmet Need and Fertility in Nepal. Further analysis of the 2011 Nepal Demographic and Health Survey," Nepal Ministry of Health and Population, New ERA, and ICF International, Calverton, Md, USA, 2013.
[23] D. Thomas, S. Bell, K. Dahal et al., Voices from the Community: Access to Health Services; A Rapid Participatory Ethnographic Evaluation and Research (PEER) Study, Nepal, Government of Nepal ( GoN ), Population Division; Ministry of Health and Population ( MoHP ), with support from; Nepal Health Sector Support Programme (NHSSP), Kathmandu, Nepal, 2012.

[24] S. K. Sharma, D. R. Ghimire, and N. Pratap, "Ethnic differentials of the impact of the family planning program on contraceptive use in Nepal," Demographic Research, vol. 25, article 27, pp. 837868, 2011.

[25] F. Najafi-Sharjabad, S. Zainiyah Syed Yahya, H. Abdul Rahman, M. Hanafiah Juni, and R. Abdul Manaf, "Barriers of modern contraceptive practices among Asian women: a mini literature review," Global Journal of Health Science, vol. 5, no. 5, pp. 181192, 2013.

[26] T. Lutalo, M. Kidugavu, M. J. Wawer, D. Serwadda, L. S. Zabin, and R. H. Gray, "Trends and determinants of contraceptive use in Rakai District, Uganda, 1995-98," Studies in Family Planning, vol. 31, no. 3, pp. 217-227, 2000.

[27] A. H. Ibnouf, H. W. van den Borne, and J. A. Maarse, "Utilization of family planning services by married Sudanese women of reproductive age," Eastern Mediterranean Health Journal, vol. 13, no. 6, pp. 1372-1381, 2007.

[28] J. M. Tuladhar, "Emergence and development of Nepal's family planning program," in The Global Family Planning Revolution: Three Decades of Population Policies and Programs, 2007.

[29] M. Chetri, A. Bhatta, R. N. Amatya et al., "Five-year evaluation of safety, efficacy and acceptability of Norplant implants in Nepal," Advances in Contraception, vol. 12, no. 3, pp. 187-199, 1996.

[30] M. Rao, K. D. Rao, A. S. Kumar, M. Chatterjee, and T. Sundararaman, "Human resources for health in India," The Lancet, vol. 377, no. 9765, pp. 587-598, 2011.

[31] S. Mehata, Y. R. Paudel, R. Mehta, M. Dariang, P. Poudel, and S. Barnett, "Unmet need for family planning in Nepal during the first two years postpartum," BioMed Research International, vol. 2014, Article ID 649567, 9 pages, 2014. 


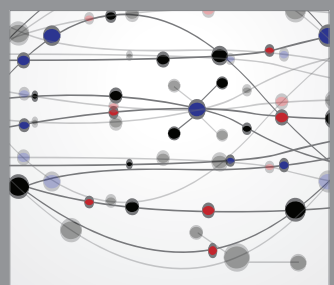

The Scientific World Journal
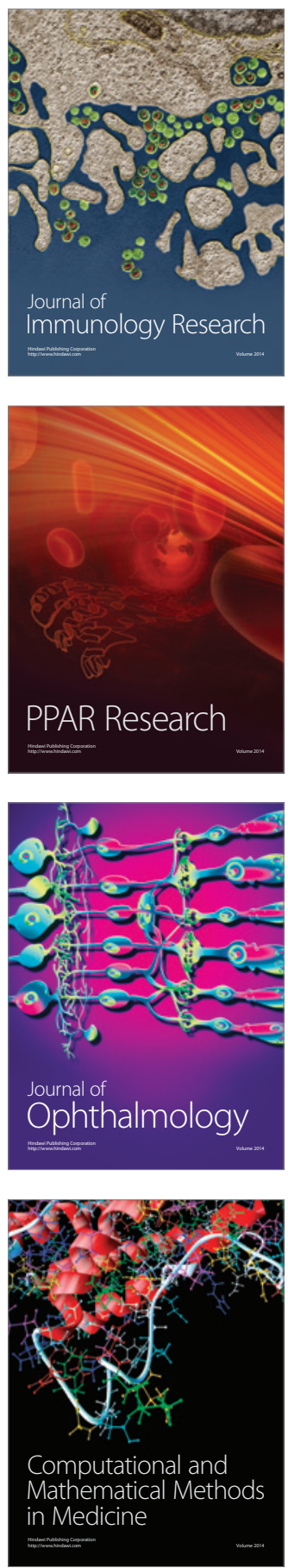

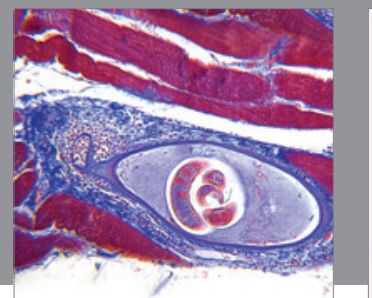

Gastroenterology

Research and Practice
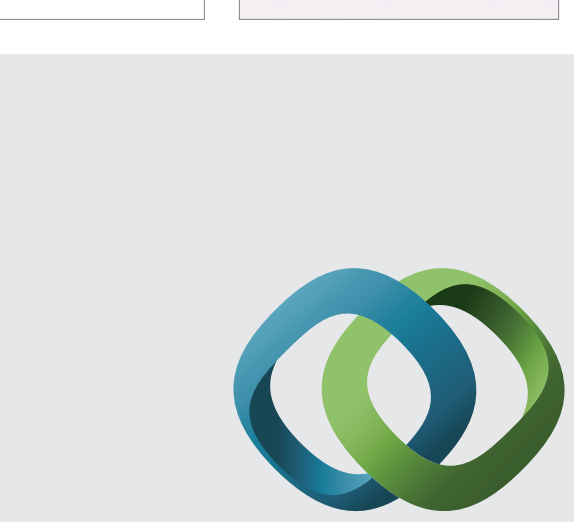

\section{Hindawi}

Submit your manuscripts at

http://www.hindawi.com
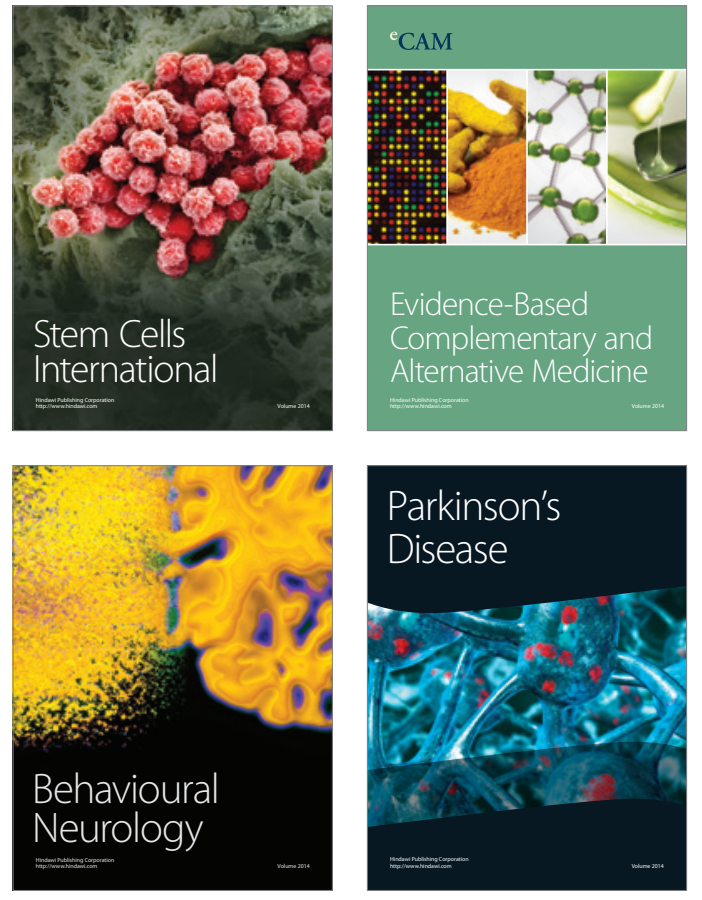
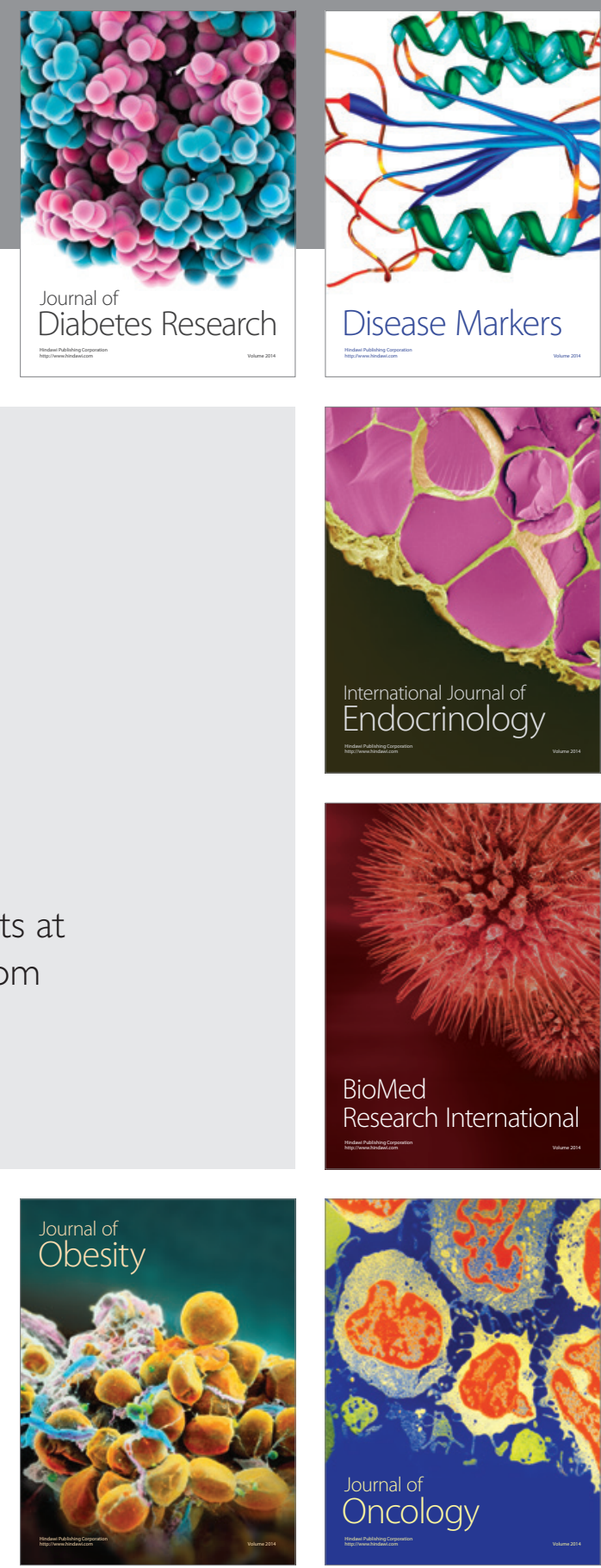

Disease Markers
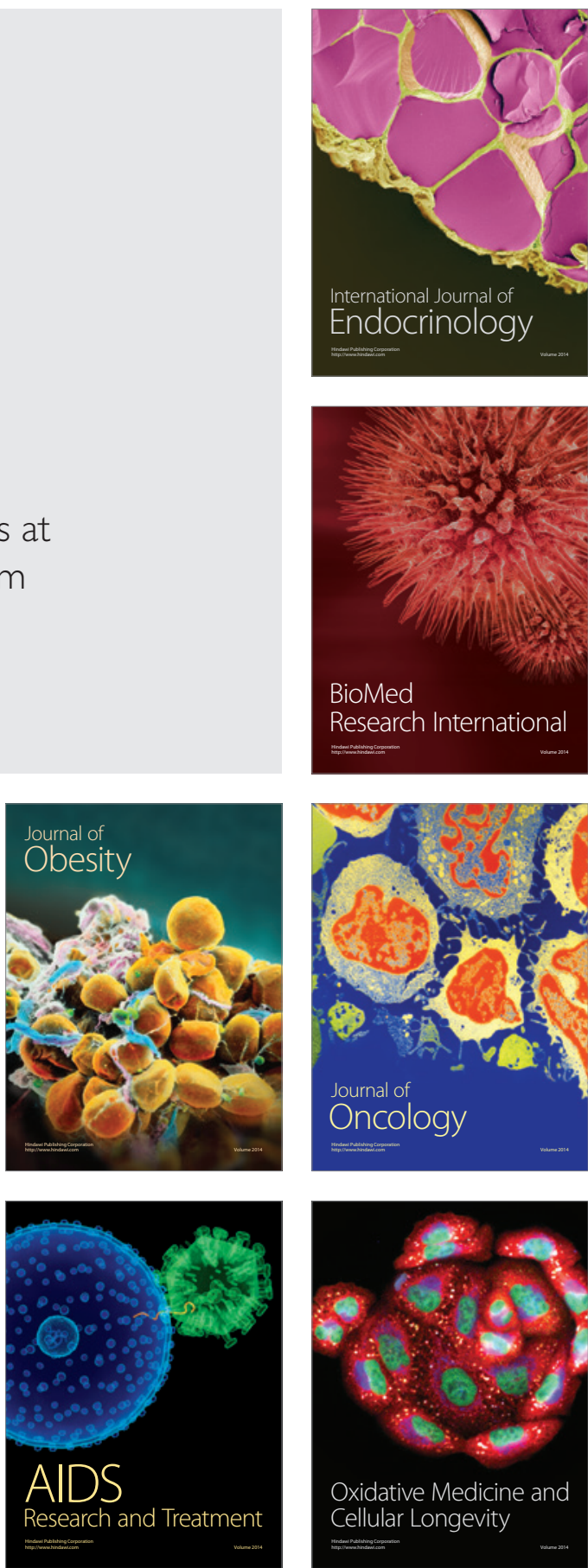